\title{
Trace Element Levels in Urban Ghanaian Pregnant Women
}

\author{
Efua Amuaba Appiah*, George Awuku Asare \\ Chemical Pathology Unit, Department of Medical Laboratory Sciences, School of Allied Health Sciences, College of Health \\ Sciences, University of Ghana, Accra, Ghana \\ Email: *appiah.efua1@yahoo.com
}

How to cite this paper: Appiah, E.A. and Asare, A. (2020) Trace Element Levels in Urban Ghanaian Pregnant Women. Open Journal of Obstetrics and Gynecology, 10, 1658-1668.

https://doi.org/10.4236/ojog.2020.10110149

Received: October 12, 2020

Accepted: November 27, 2020

Published: November 30, 2020

Copyright $\odot 2020$ by author(s) and Scientific Research Publishing Inc. This work is licensed under the Creative Commons Attribution International License (CC BY 4.0).

http://creativecommons.org/licenses/by/4.0/

\section{(c) (i) Open Access}

\begin{abstract}
The trace elements used in the study are zinc, copper, selenium and iron, these have been implicated in various reproductive events. Maternal trace elements intake and their concentration are important for maternal and fetal well-being; however, data is insufficient in Ghanaian pregnant women. Especially, their concentration according to the pregnancy course $\left(1^{\text {st }}, 2^{\text {nd }}\right.$, and $3^{\text {rd }}$ trimester) should be determined, which may provide fundamental data of this issue. The maternal blood levels of four trace elements: zinc, copper, selenium and iron, were determined according to the gestational age in Ghanaian pregnant women. Blood samples were taken from 150 pregnant women (50 for each trimester) and 50 non-pregnant women (control). Concentration of four trace elements was measured using Flame Atomic Absorptive Spectrophotometer. The data (mean $\pm \mathrm{SD}$; ug/L) was as follows: in the order of control, $1^{\text {st }}, 2^{\text {nd }}$, and $3^{\text {rd }}$ trimester. 1) For zinc, $313 \pm 211,101 \pm 92,66 \pm 63$, and $443 \pm 321.2$ ) For copper, $345 \pm 261,1349 \pm 418,1507 \pm 388$, and $1811 \pm 344$. 3) For selenium, $99 \pm 25,56 \pm 17,163 \pm 38$, and $261 \pm 84$. 4) For iron, $43.2 \pm$ 15.2, $27.3 \pm 15.7,28.7 \pm 17.2$, and $40.5 \pm 17 \mathrm{ug} / \mathrm{L}$. Although each trace element showed various/specific concentrations according to the gestational age, overall tendency was a decline at $1^{\text {st }}$ and $2^{\text {nd }}$ trimester, and increase at $3^{\text {rd }}$ trimester. The latter may be due to the introduction of supplementation. These data may be of use to consider maternal nutritional status in this area. Objective: To estimate the levels of zinc, copper, iron and selenium in pregnancy. Subjects were recruited from the Osu Maternity Home (OMH).
\end{abstract}

\section{Keywords}

Zinc, Copper, Selenium, Chromium, Supplementation

\section{Introduction}

In the human body, there is a need for essential minerals such as trace elements 
for normal development and functioning of the body. These trace elements are needed in minute quantities in the body but are mostly limiting in the diets, particularly of the socio-economically weaker and physiologically venerable sections of the population in developing countries [1]. Deficiencies of these trace elements have been documented to play a major role in the determination of fetal outcome. In developing countries, the diet of pregnant women is noted to contain lower amount of minerals and vitamins [1]. Trace elements like zinc, copper and magnesium have been implicated in various reproductive events like fertility, pregnancy induced hypertension, placental abruption, premature rupture of membranes, pregnancy wastage, congenital anomalies, still births and low birth weight [1].

Copper, Zinc and Selenium are essential for normal human development and functioning of the body [2]. They also play important roles in immune physiologic functions, for e.g. Zinc plays a significant role in nucleic acid metabolism, forms an integral part of more than 200 enzymes, cell replication, tissue repair and growth. Lack of zinc in the system leads to profound alteration of thymic function with resultant loss of T-cell-mediated responses and increased susceptibility to infectious diseases [3]. The anti-oxidation function of selenium in glutathione peroxidase is essential in protecting the biological system from oxidation caused by peroxides. Superoxide dismutase, which usually contains copper and or zinc, acts as antioxidants against superoxide [2].

In developing countries, deficiency of minerals and vitamins in women of reproductive age is recognized as a major public health concern. Pregnant women are the prime target as far as nutritional deficiencies are concerned. The demands imposed by pregnancy involving the growing placenta, fetus and maternal tissues, coupled with associated dietary risks could add up to the effect. If there should be a comprised of nutrition during pregnancy, it can result in adverse effects such as anemia, pregnancy-induced hypertension, complications of labor and even death [4]. Furthermore, the fetus can be affected, resulting in stillbirth, pre-term delivery, intrauterine growth retardation, congenital malformations, reduced immuno-competence, and abnormal organ development.

Deficiency of trace elements like zinc, copper and magnesium have been implicated in the various reproductive events like pregnancy induced hypertension, stillbirths and low birth weight. The level of multiple trace elements in Ghanaian pregnant women has so far (to the best of our knowledge) not been well documented. Whether levels are adequate or not remains a perception and a matter of conjecture. There is a need therefore to undertake studies in this field.

\section{Methodology}

\subsection{Study Site}

Subjects were recruited from the Osu Maternity Home (OMH). The maternity home serves the Osu-Klottey constituency in the Greater Accra region. At OMH patients attend antenatal care and are only detained prior to delivery. 


\subsection{Study Design}

The study design was a cross-sectional study and was conducted from December 2009 to April 2010.

\subsection{Subjects}

Blood sample was taken from pregnant women within the ages of 23 - 35 years who report for antenatal clinic. At least 50 samples were taken for the various trimesters. A total number of 200 samples were taken, including control samples. Since this is a cross-sectional study, the mean, standard deviations and variance were looked at.

\section{Inclusion Criteria and Exclusion Criteria}

Pregnant women reporting to the Osu maternity home were used in the study. Men, non-pregnant women and pregnant women whose stool later show positive for worms.

\subsection{Sample Size}

A total of 200 samples were taken for the analysis. This comprised of 150 pregnant women and 50 non-pregnant women (control samples). Since this is a cross-sectional study, the mean, standard deviations and variance were determined.

\section{Sample size determination}

$$
N=\frac{Z^{2} \cdot S^{2}}{D^{2}}
$$

$N=(200)$ sample size;

$D=$ allowable error;

$Z(\alpha=95 \%)=1.96$;

$S=$ standard deviation (Schagen et al., 2006), $S=0.9, S^{2}=0.81 \%$.

$$
\begin{gathered}
D^{2}=\frac{Z^{2} \cdot S^{2}}{N} \\
D=\sqrt{\frac{Z^{2} \cdot S^{2}}{N}} \\
D=\sqrt{\frac{1.96^{2} \cdot 0.9^{2}}{200}} \\
D=\sqrt{\frac{3.112}{200}} \\
D=\sqrt{0.016}
\end{gathered}
$$

$D=0.13, D=133.4$

\subsection{Sample Collection and Preparation}

3 - 5 mls of blood samples were taken into plain tubes and allowed to clot. It was then centrifuged at $3000 \mathrm{rpm}$ for 5 minutes and supernatant pipetted into clean 
tubes. The serum was stored at $-20^{\circ} \mathrm{C}$ for analysis later.

\subsection{Materials}

$6 \mathrm{mls}$ of $69 \%$ Nitric acid $\left(\mathrm{HNO}_{3}\right)$.

$1 \mathrm{ml}$ of $30 \%$ Hydrogen peroxide $\left(\mathrm{H}_{2} \mathrm{O}_{2}\right)$.

\subsection{Flame Atomic Absorptive Spectrophotometer}

\section{Principle of FAAS}

VARIAN 240FS Flame Atomic absorption (FAAS) spectrophotometer was used along with standards of high purity metals from Teknolab AS Sweden, to assay the elements quantitatively. Atomic absorption Spectrometer is an instrument which quantitatively measures the concentrations of elements present in a liquid sample. It utilizes the principle that elements in the gaseous phase absorb light at very specific wavelengths. This gives the technique excellent specificity and detection limits. The liquid is drawn into a flame where it is ionized in the gaseous phase. Light of specific wavelength is shone through the flame. The absorption is proportional to the concentration of the elements. The analytical conditions of the elements are listed in Table 1.

\subsection{Sample Preparation Prior to Atomic Absorption Spectrometry and Assay}

Digestion of the samples was carried out to get rid of the organic component leaving only the trace elements to be analyzed. $1 \mathrm{ml}$ of the serum samples were weighed accurately into TFM Teflon Vessels of a microwave digester (Milestone ETHOS 900). $6 \mathrm{mls}$ of $69 \% \mathrm{HNO}_{3}$ and $1 \mathrm{ml}$ of $30 \% \mathrm{H}_{2} \mathrm{O}_{2}$ were added to each vessel containing the sample. The vessels were swirled gently to mix well and fitted vertically into the microwave digester and digested for 25 minutes. The samples were digested using $6 \mathrm{mls}$ of $\mathrm{HNO}_{3}$ and $1 \mathrm{ml}$ of $\mathrm{H}_{2} \mathrm{O}_{2}$. Once digestion was completed, the solution containing the samples was cooled down in a water bath for 10 minutes to reduce high temperature and pressure built up within the vessels. The digestive component was then transferred quantitatively into a volumetric flask and diluted to $20 \mathrm{mls}$ using deionized water. A blank was prepared in a similar fashion but without the analyte. All the samples were analyzed using VARIAN 240FS flame atomic absorption spectrometer. To ensure the reliability of the analytical method during digestion and sample preparation, blank samples were also digested along with each set of samples and subsequently analyzed for appropriate elements through the same procedure.

Table 1. Analytical conditions of elements.

\begin{tabular}{cccccc}
\hline Element & Lamp Current $(\mathrm{mA})$ & Wavelength $(\mathrm{nm})$ & Slit width $(\mathrm{nm})$ & Fuel Gas & Oxidant \\
\hline $\mathrm{Zn}$ & 5 & 213.9 & 0.1 & Acetylene & Air \\
$\mathrm{Cu}$ & 4 & 327.4 & 0.1 & Acetylene & Air \\
$\mathrm{Se}$ & 10 & 196.0 & 1.0 & Acetylene & Air \\
$\mathrm{Fe}$ & 4 & 248.3 & 0.1 & Acetylene & Air \\
\hline
\end{tabular}




\subsection{Statistical Analysis}

The data obtained will be entered into a database using SPSS Windows 11.5, Microsoft. The mean \pm SD will be calculated. Student's $t$ test will be determined and considered significant at $\mathrm{p}<0.05$. ANOVA and correlation analysis will be performed to determine the degree of correlations.

\section{Results}

Blood samples were taken from pregnant women within the ages of 23 - 35 years who report for antenatal clinic at the OMH. At least 50 samples were taken for the various trimesters. A total number of 150 samples were taken, excluding the control samples.

From Figure 1, the mean controls of zinc levels were $313 \pm 211 \mathrm{ug} / \mathrm{L}$. That for the first, second and third trimesters are $101 \pm 92 \mathrm{ug} / \mathrm{L}, 66 \pm 63 \mathrm{ug} / \mathrm{L}$ and $443 \pm$ $321 \mathrm{ug} / \mathrm{L}$ respectively. Furthermore, the mean controls reading was statistically significant compared to the first trimester $(\mathrm{p}<0.002)$, second trimester $(\mathrm{p}<$ $0.002)$ and the third trimester $(\mathrm{p}<0.002)$.

In Figure 2, the mean control levels of copper were $345 \pm 261 \mathrm{ug} / \mathrm{L}$. Those for first, second and third trimesters were $1349 \pm 418 \mathrm{ug} / \mathrm{L}, 1507 \pm 388 \mathrm{ug} / \mathrm{L}$ and $1811 \pm 344 \mathrm{ug} / \mathrm{L}$, respectively. Comparing the mean of the control to that of the various trimester groups, statistically, differences were seen when compared to the first $(\mathrm{p}<0.001)$, second $(\mathrm{p}<0.001)$ and third $(\mathrm{p}<0.001)$.

For that of iron from Figure 3, the mean for the control levels was $43.2 \pm 15.2$ $\mathrm{ug} / \mathrm{L}$. Those of the first, second and third trimesters were $27.3 \pm 15.7 \mathrm{ug} / \mathrm{L}, 28.7$ $\pm 17.2 \mathrm{ug} / \mathrm{L}$ and $40.5 \pm 17 \mathrm{ug} / \mathrm{L}$, respectively. Statistically, the mean of the control was significantly different from that of the first trimester $(p<0.001)$, second trimester $(\mathrm{p}<0.001)$ and the third trimester $(\mathrm{p}<0.001)$.

The mean control levels of selenium were $99 \pm 25 \mathrm{ug} / \mathrm{L}$. The results of the various trimesters were as follows: first trimester was $56 \pm 17 \mathrm{ug} / \mathrm{L}$, the second trimester was $163 \pm 38 \mathrm{ug} / \mathrm{L}$ and that of the third trimester was $261 \pm 84 \mathrm{ug} / \mathrm{L}$. Further comparison of the control mean to the first, second and third trimesters were statistically significant of $\mathrm{p}<0.001, \mathrm{p}<0.001$ and $\mathrm{p}<0.001$ (Figure 4).

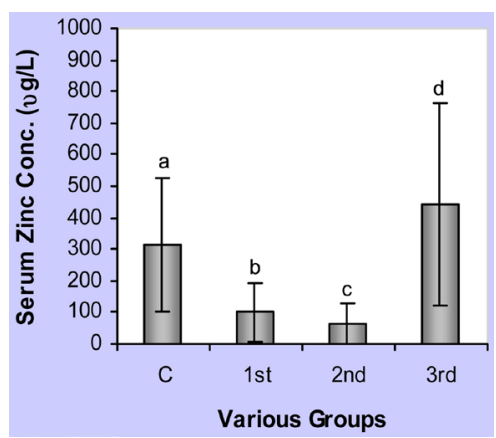

Figure 1. Results of the mean Zinc levels of the various trimester groups. The control group (a) was statistically different from all the other groups; ((b), (c) and (d)): (p < $0.001 ; \mathrm{p}<0.001 ; \mathrm{p}<0.001$ respectively). Furthermore, the second trimester Zinc levels were statistically different from that of the third trimester group $(\mathrm{p}<0.000)$. 


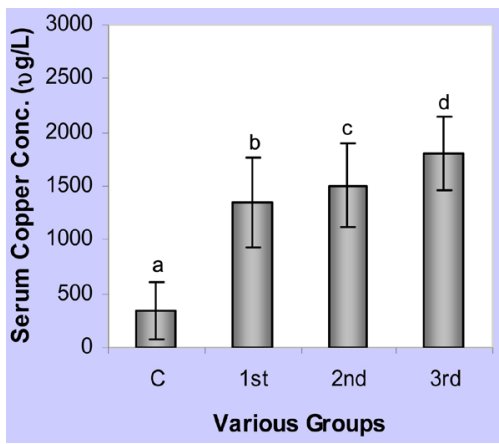

Figure 2. Results of the mean Copper levels of the various trimester groups. The control Copper levels (a) were very low compared to the first (b), second (c) and the third (d) trimester groups ( $\mathrm{p}<0.001$ respectively). Furthermore, differences between the first and the third trimester groups ( $b$ and $d)$ were statistically different $(p<0.001)$.

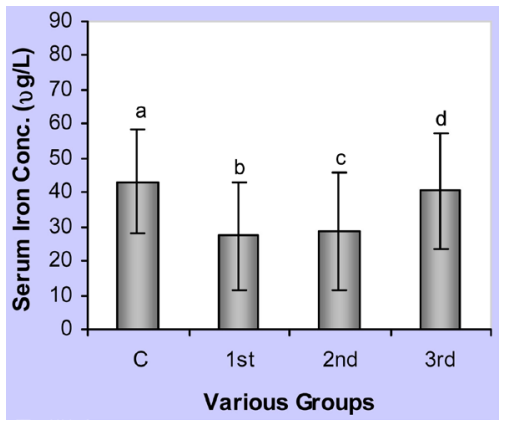

Figure 3. Results of the mean Iron levels for the various trimester groups and the control statistically. The control (a) was different from the first (b) and the second (c) trimester groups. However, the control (a) and the third trimester group (d) were not statistically different. Moreover, the third trimester Iron levels (d) were statistically different from the first (b) and the second (c) trimester groups ( $\mathrm{p}<0.017 ; \mathrm{p}<0.05$, respectively).

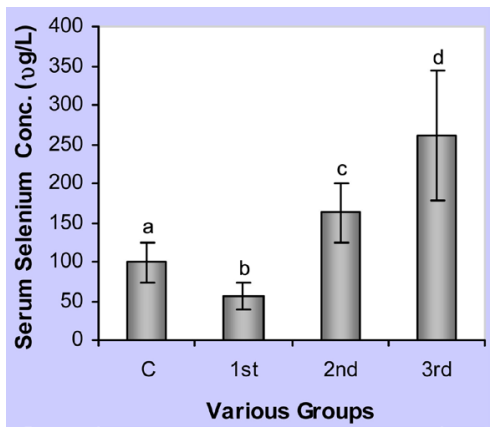

Figure 4. Results of the mean Selenium levels of the first (b), second (c) and the third (d) trimester groups and the control group (a). The control group (a) was statistically different from $b, c$, and $d(p<0.001 ; p<0.001 ; p<0.001$ respectively). Furthermore, $b$ was statically different from $\mathrm{c}(\mathrm{p}<0.001)$ and $\mathrm{d}(\mathrm{p}<0.001)$. The second trimester group $(\mathrm{c})$ and the third trimester group (d) also showed differences that were statistically significant.

\section{Discussion and Conclusion}

From the study, there was a general increase in zinc levels of the pregnant subjects compared to the control subjects. Generally, Zn levels are expected to de- 
crease between $28 \%$ - $30 \%$ during pregnancy compared to control subjects. In this study, a decline was observed in the first trimester and a further decline in the second trimester of pregnancy due to increased demand of the element from the growing fetus. There was a drastic increase in the level of $\mathrm{Zn}$ in the third trimester of pregnancy. Other findings confirmed that the level of $\mathrm{Zn}$ decreased with increasing gestational periods especially within the first 15 weeks of gestation. That study further observed that zinc levels even became lower in the 16 $20^{\text {th }}$ week of gestation and this was attributed to the volume expansion in the pregnant woman of which the peak was reached in the final or third trimester of pregnancy [5].

Other factors noted to affect maternal $\mathrm{Zn}$ levels in pregnancy include the intake of iron supplementation which affects the absorption of $\mathrm{Zn}$. An intriguing interaction appears to exist between zinc and iron in absorption and utilization. This is because the supplementation of iron has been reported to affect bioavailability of zinc in iron deficiency anemia by inter element competition in the bowel. Furthermore, diet rich in fiber, phytate and calcium will equally reduce the availability of $\mathrm{Zn}$ in the mother's system and maternal stress which increases the synthesis of metallothionein and this has a strong affinity for $\mathrm{Zn}$ affecting it release. This effect is mostly overshadowed in the final or third trimester of pregnancy when the effect of supplementation becomes evident. Subsequently increases of the element are observed [6].

The causes of zinc deficiency in pregnancy are multiple. These include low dietary intake, elemental interactions during supplementation, environmental and physiological conditions such as exercise, infections, inflammations and hypertension. Low levels are seen in women with higher parity, while on the other hand, bioavailability of copper and iron are affected by zinc supplementation.

Copper levels increase with gestational age as well as increased levels of maternal oestrogen level therefore its increase is observed from the figure above with subsequent progression in pregnancy. A gradual increase is observed from the first to the third trimester of pregnancy. This of course is absent in the control group who are non-pregnant subjects and do not observe an increase in oestrogen level. These findings were also confirmed by Baig et al. [7] in his study of $\mathrm{Cu}, \mathrm{Zn}$ and Se in maternal and cord blood.

Finding from other studies adds to the fact that levels of $\mathrm{Cu}$ increased in the various stages of pregnancy and stabilized over time till delivery. High levels of $\mathrm{Cu}$ in maternal serum could be dangerous for the fetus and could cause cerebral disorder and could induce abortion in the mother [5]. However, deficiency of $\mathrm{Cu}$ is rare, but if it should occur, it is likely due to malnutrition especially with sparingly intake of cereal-based diets, malabsorption and gastrointestinal diseases. Other factors include multiple supplementation which conflicts with $\mathrm{Cu}$ absorption, infections, inflammation, hypertension, diabetes mellitus and effect of dietary inhibitors [8].

Furthermore, the increase in $\mathrm{Cu}$ was caused by a parallel increase in Cu's major binding protein ceruloplasmin which increased as a result of elevated levels 
of maternal oestrogen. Again, $\mathrm{Cu}$ concentration increase during the last 3 months of pregnancy and decrease after delivery. Cu level was found to be high in women who have had more deliveries [9].

Maximum increase in copper was observed during week 35 - 36 and this is most likely to be dependent on the requirement of the fetus for growth and this is similarly observed in another study done [10]. It is likely that inadequate $\mathrm{Cu}$ stores predispose premature infants to the risk of copper deficiency. Copper stores are especially important during development. As shown by the studies of Widdowson et al. [11] fetal copper stores accumulate primarily during the last trimester of pregnancy.

Iron deficiency continues to be one of the most prevalent single-nutrient deficiencies in the world. Interventions are often designed to prevent the decrease in hemoglobin concentration and the decline in iron stores associated with pregnancy. Enrichment and fortification of food items, and dietary changes resulting from educational interventions, have met with some success in developed countries, but not often in the developing world [12]. Large doses of iron are most often prescribed and are associated with side effects and with increased oxidative stress. In the pregnant woman, iron is transferred from one body compartment to another in the plasma iron pool, bound to the iron transporting protein transferrin. On reaching the placenta, iron is transported across the placental barrier by an active process involving the specific transporter of divalent metal ions [13]. The woman's transferrin-bound iron is then coupled to transferrin receptors in placenta. Subsequently, iron is transported through the maternal-fetal barrier into the fetal circulation [14]. The transport system ensures that fetal supply of iron is widely independent of the woman's iron status. Consequently, clinically overt fetal iron deficiency occurs only by marked iron deficiency in the woman.

Ideally all women of childbearing age should have sufficient stores of iron to cope with the metabolic demands made by pregnancy which can be met without further increase because of cessation of menstrual losses and by mobilization of maternal iron stores and increased intestinal absorption. However, when iron stores are inappropriately low at the start of pregnancy, supplementation with iron may be necessary [15].

Iron levels from the results obtained in the study show that the control subjects have a high storage of iron which was almost at par with that of the third trimester group. These are the control group with good eating habits. A gradual increase was observed for the various trimester's groups of pregnancy. This trend was obviously altered by supplementation since hemoglobin estimation is routinely done in the maternity home. The physiologic solution for mitigating the high iron requirements in pregnancy is to use iron from iron stores. The problem, however, is that very few women, if any, have iron stores of this magnitude. Therefore, daily iron supplements are recommended in the latter half of pregnancy [16]. Thus, Iron requirements in the second and third trimesters cannot be resolved by dietary iron alone, even if it is of high bioavailability and, 
unless stores of about $500 \mathrm{mg}$ are believed to exist before pregnancy, administration of iron supplements may be required if impairment of the expected increase in hemoglobin mass in the mother is to be avoided [17].

In this study selenium level for the control group was normal, unlike the various trimester groups where there was an increase from the first to the third. Selenium in recent times has attracted particular attention especially its biochemistry, toxicology and nutritional. Selenium status is particularly of importance in neonates and infants and therefore in pregnant women. Selenium levels are dependent on factors such as nutritional habits, sex and geographical location. Selenium is helpful in maintaining anti-oxidative status against the endogenous oxidative stress products, this element may offer protection to the pregnant women and the fetus [7].

It is generally accepted that selenium requirements of pregnant women increase as a result of selenium transport to the fetus. The concentration of selenium in the placenta and amniotic membranes is much higher than in maternal blood, which suggests the presence of an active transport system for selenium in the placenta, although the optimum selenium intake during pregnancy is unknown. It was calculated that at least $100 \mathrm{mg}$ of dietary selenium per day is needed for optimum balance. Deficiency of selenium could be associated with various abnormalities in the fetus. One of the contributory causes for the pregnancy-related oxidative stress is the decline in selenium status during pregnancy. Decrease in selenium concentrations which progresses as gestation proceeds [18] may be partly attributed to hemodilution from blood volume increases associated with pregnancy [19].

\section{Conclusion and Recommendation}

The graphical presentation of the results obtained indicated a decline of the levels of zinc for the first and second trimesters respectively with a marked increase in the third trimester of pregnancy which is due to the introduction of supplementation. There was also a decline in the iron level in the first two trimester groups which was corrected with supplementation to ensure its increase in the third trimester of pregnancy. The same trend was observed for selenium as well. The corrective effect was the introduction of multivitamin incorporated with micronutrients supplements and these include drugs like Zincovet, Ferroglobin and Pregnant Care to mention a few. On the other hand, there was a steady increase in the levels of copper for all three trimester groups of pregnancy in the absence of copper supplementation since levels of copper increase with an increase in maternal oestrogen. The issue therefore is that supplementation should be taken seriously to avert a decline in the levels of zinc, selenium and iron respectively but on the other hand, the level of copper should be monitored and moderated.

\section{Acknowledgements}

My profound appreciation goes to my Heavenly Father for seeing me through 
this work successfully.

Then to my lecturer and supervisor, Dr. George Asare, I pray God Almighty bless you for your time, resources and your pieces of advice.

To my second supervisor, Dr. Shiloh at Ghana Atomic Energy, I am so grateful for your support in analyzing my samples.

To all lecturers of School of Allied Health Sciences and especially to those of Chemistry Department I say a big thank for your effort.

My appreciation goes to the pregnant women and the laboratory staff at Osu Maternity Home who participated to make this work a success.

To Mr. Nash Bentil and his team at Ghana Atomic Energy Commission I say a big thank for all your effort and support.

To my course mates, thanks so much, we are all in this together to achieve our goal.

\section{Conflicts of Interest}

The authors declare no conflicts of interest regarding the publication of this paper.

\section{References}

[1] Pathak, P. and Kapil, U. (2004) Role of Trace Elements Zinc, Copper and Magnesium during Pregnancy and Its Outcome. Indian Journal of Pediatrics, 71, 1003-1005. https://doi.org/10.1007/BF02828116

[2] WHO (1996) Trace Elements in Human Nutrition and Health. WHO, Geneva, 72-104.

[3] Failla, M.L. (2003) Trace Elements and Host Defense: Recent Advances and Continuing Challenges. Journal of Nutrition, 133, 1443S-1447S. https://doi.org/10.1093/jn/133.5.1443S

[4] King, J.C. (2000) Physiology of Pregnancy and Nutrient Metabolism. The American Journal of Clinical Nutrition, 71, 1218-1225. https://doi.org/10.1093/ajcn/71.5.1218s

[5] Scheplyagina, L.A. (2005) Impact of the Mother's Deficiency on the Woman's and the Newborn's Health Status. Journal of Trace Elements in Medicine and Biology, 19, 29-35. https://doi.org/10.1016/j.jtemb.2005.07.008

[6] Siassakos, D. and Wardle, P. (2007) Polycystic Ovary Syndrome and Pregnancy Outcome: Red Herring or Red Flag? The International Journal of Gynecology \& Obstetrics, 114, 922-932. https://doi.org/10.1111/j.1471-0528.2007.01418.x

[7] Baig, S., Hasnian, N.U. and Ud-Din, Q. (2003) Studies on Zn, Cu, Mg, Ca and Phosphorous in Maternal and Cord Blood. Journal of Pakistan Medical Association, 53, 417.

[8] Barasi, M.E. (1997) Human Nutrition: A Health Perspective. Oxford University Press, New York, 187-189.

[9] Arnaud, J., Prual, A., Freziosi, et al. (1993) Effect of Iron Supplementation during Pregnancy on Trace Elements $(\mathrm{Cu}, \mathrm{Se}, \mathrm{Zu})$ Concentrations in Serum and Breast Milk from Nigerian Woman. Annals of Nutrition and Metabolism, 37, 262-271. https://doi.org/10.1159/000177776

[10] Al-Bader, A., Hussain, T., Al-Mosawi, M., Otaibi, M., Abul, H., Khalifa, D., et al. (1997) Serum Zinc and Copper Concentrations in Pregnant Women from Kuwait. 
The Journal of Trace Elements in Experimental Medicine, 10, 209-215. https://doi.org/10.1002/(SICI)1520-670X(1997)10:4<209::AID-JTRA1>3.0.CO;2-4

[11] Widdowson, E.M., Dauncey, J. and Shaw, J.L.C. (1974) Trace Elements in Foetal and Early Postnatal Development. Proceedings of the Nutrition Society, 33, 275-284. https://doi.org/10.1079/PNS19740050

[12] Beard, J.L. (2000) Effectiveness and Strategies of Iron Supplementation during Pregnancy. American Journal of Clinical Nutrition, 71, 1288s-1294s. https://doi.org/10.1093/ajcn/71.5.1288s

[13] Georgieff, M.K., Berry, S.A., Wobken, J.K., Welle, J., Burdo, J.R., et al. (2000) Identification and Localization of Divalentmetal Transporter-1 (DMT-1) in Term Human Placenta. Placenta, 21, 799-804. https://doi.org/10.1053/plac.2000.0566

[14] Bergamaschi, G., Bergamaschi, P., Carlevati, S. and Cazzola, M. (1990) Transferrin Receptor Expression in the Human Placenta. Haematologica, 75, 220-223.

[15] Mast, A.E., Blinder, M.A., Lu, Q., et al. (2002) Clinical Utility of the Reticulocyte Hemoglobin Content in the Diagnosis of Iron Deficiency. Blood, 99, 1489-1491. https://doi.org/10.1182/blood.V99.4.1489

[16] Ghio, A.J., Carter, J.D., Richards, J.H., et al. (2003) Iron and Iron-Related Proteins in the Lower Respiratory Tract of Patients with Acute Respiratory Distress Syndrome. Critical Care Medicine, 31, 395-400. https://doi.org/10.1097/01.CCM.0000050284.35609.97

[17] WHO/FAO/IAEA (1996) Trace Elements in Human Nutrition and Health. World Health Organisation, Geneva.

[18] Zachara, B.A., Wardak, C., Didkowski, W., Maciag, A. and Marchaluk, E. (1993) Changes in Blood Selenium and Glutathione Concentrations and Glutathione Peroxidase Activity in Human Pregnancy. Gynecologic and Obstetric Investigation, 35, 12-17. https://doi.org/10.1159/000292655

[19] Ferrer, E., Algeria, A., Barabara, R., Farre, R., Largarda, M.J., et al. (1999) Whole Blood Selenium Content in Pregnant Women. Science of the Total Environment, 227, 139-143. https://doi.org/10.1016/S0048-9697(99)00008-X 